Acta Protozool. (2018) 57: 145-151 www.ejournals.eu/Acta-Protozoologica doi:10.4467/16890027AP.18.012.8986 PROTOZOOLOGICA

\title{
Morphology and Sequence Data of Mexican Populations of the Ciliate Parasite of Marine Fishes Trichodina rectuncinata (Ciliophora: Trichodinidae)
}

\author{
Alma G. ISLAS-ORTEGA ${ }^{1,4}$, Rogelio AGUILAR-AGUILAR ${ }^{1}$, Paula MARCOTEGUI ${ }^{2}$, \\ Sergio MARTORELLI², David HERNÁNDEZ-MENA ${ }^{3}$, Gerardo PÉREZ-PONCE DE LEÓN ${ }^{3}$ \\ ${ }^{1}$ Departamento de Biología Comparada, Facultad de Ciencias, Universidad Nacional Autónoma de México, México; ${ }^{2}$ Centro de \\ Estudios Parasitológicos y de Vectores, (CONICET-UNLP), La Plata, Argentina; ${ }^{3}$ Instituto de Biología, Universidad Nacional \\ Autónoma de México, México, D.F., México; ${ }^{4}$ Posgrado en Ciencias Biológicas, Facultad de Ciencias, Universidad Nacional \\ Autónoma de México
}

\begin{abstract}
Trichodina rectuncinata is one of the trichodinids most widely distributed in marine fish. This ciliate species has been recorded in more than 20 host species belonging to 17 fish families worldwide. Previous comparative studies based on morphometric data revealed considerable morphological variation among specimens from different populations of $T$. rectuncinata. In this study, we conducted a morphometric-molecular analysis of three populations of $T$. rectuncinata to evaluate potential differences among $18 \mathrm{~S}$ rRNA sequences, in relation to morphological variations. Smears were obtained from marine fishes in three localities along the Pacific coast of Mexico. Based on the shape of denticles, we found four different morphotypes for T. rectuncinata. This morphological variability does not correspond with the genetic divergence, suggesting that all analyzed populations belong to the same species. Further analyses using more variable markers are necessary to corroborate the findings of our study.
\end{abstract}

Key words: Ciliophora, morphology, genetic divergence, Mexico

\section{INTRODUCTION}

Ciliates of the genus Trichodina are among the most common fish parasites and are frequently found on the gills or skin of their host (Lom and Dyková 1992). The genus includes nearly 170 nominal species which are

Address for correspondence: Alma G. Islas-Ortega, Departamento de Biología Comparada, Facultad de Ciencias, Universidad Nacional Autónoma de México, Apartado Postal 70-399, C. P. 04510 México D.F., México; E-mail: alisor.721@gmail.com usually recorded from different localities around the world; therefore, most of the species are considered widespread (Dobberstein and Palm 2000). The dispersion of these ciliates is facilitated by having low host specificity, although the level of host specificity is a matter of debate among specialists (Basson and Van As 2006). Trichodina rectuncinata Raabe, 1958 is one of the trichodinids most widely distributed in marine fish. This ciliate has been recorded from more than 20 host species belonging to 17 fish families worldwide (Xu et al. 2001; Aguilar-Aguilar and Islas-Ortega 2015; 
Aguilar-Aguilar et al. 2016). Previous comparative studies based on morphometric data (e.g., Loubser et al. 1995) reveal considerable morphological variation among specimens from different populations of $T$. rectuncinata, however, some characters such as a triangular blade and a triangular or pyriform cavity in the center of each blade, appear to be sufficiently reliable to accomplish the alpha-taxonomy of this group of ciliates (Loubser et al. 1995; Xu et al. 2001).

However, the identification of Trichodina species remains to be a challenge. Factors that complicate species-level identification of some trichodinids are the limited morphological traits, lack of autapomorphies, and intra-specific variation in key diagnostic features (Grupcheva et al. 1989). Since morphology alone has been considered insufficient to accurately distinguish among many species of parasite organisms (Tang et al. 2017; Maciel et al. 2018), diverse molecular tools can provide independent data to test: firstly whether different morphotypes should be considered as a single independent species, secondly, if each morphotype should be considered as separate species, or thirdly, if there are evidences for separate species within a single morphotype (Nadler et al. 2000; Nadler and Pérez-Ponce de León 2011). Molecular studies using DNA markers have become a more common practice in taxonomic investigations of parasitic organisms, as an approach to deliberately search for evidence of cryptic species (Blouin 2002; Pérez-Ponce de León and Nadler 2010, Nadler and Pérez-Ponce de León 2011). In this work, we analyzed the morphology combined with genetic diversity of some populations of the widespread ciliate Trichodina rectuncinata, through the nuclear small subunit of the ribosomal RNA, in order to test the genetic uniformity of this species despite a wide morphological variation. As alternative hypothesis, high values of genetic divergence will suggest independent evolutionary lineages, and possible cryptic species complexes.

In this context, $T$. rectuncinata represents a promising model group of parasites for molecular studies because they are commonly found in several species of marine fishes over a wide geographic range. Furthermore, a molecular framework will allow us to independently evaluate morphological characters that have been traditionally used to differentiate species of trichodinids.

\section{MATERIALS AND METHODS}

\section{Collection of specimens}

Between December 2014 and February 2016, 111 individual fishes representing 14 species were examined for trichodinid. These fishes were collected using hand nets at the intertidal zone in three localities along the Pacific coast of Mexico: San Carlos, in the Gulf of California $\left(27^{\circ} 56^{\prime} \mathrm{N}, 111^{\circ} 05^{\prime} \mathrm{W}\right)$, Zihuatanejo $\left(17^{\circ} 38^{\prime} \mathrm{N}\right.$, $\left.101^{\circ} 36^{\prime} \mathrm{W}\right)$, and Cuatunalco $\left(15^{\circ} 41^{\prime} \mathrm{N}, 96^{\circ} 20^{\prime} \mathrm{W}\right)$ (Fig. 1).

Hosts were kept alive and studied for ectoparasitic ciliates no more than five hours after capture. Squash slides of gills were made from live specimens. A preliminary inspection was carried out in order to verify a mono-specific infection by $T$. rectuncinata. Smears with trichodinids were air-dried and impregnated with silver nitrate technique according to Martorelli et al. (2008).

\section{Morphological analysis}

Microphotographs of smears were obtained using Leica DM500 ${ }^{\circledR}$ photomicroscope equipment, with the Leica ICC50 HD ${ }^{\circledR}$ capture imaging system and the OLYMPUS IX81 inverted microscope. The measurements of different morphological structures such as denticles (blade, central part and ray), adhesive disc, denticular ring, and the number of denticles were obtained following the recommendations of Lom (1958). All measurements were taken in the Image-Pro Plus ${ }^{\circledR} 7.0$ software and expressed in micrometers. Denticles of organisms from each population were drawn using the GIMP (version 2.8.16). The description of the denticles followed the recommendations of Van As and Basson (1989).

\section{Molecular protocol}

\section{DNA Extraction, Amplification and Sequencing}

A set of organisms recovered from each host was fixed in vials with absolute alcohol. The vials were centrifuged in a vacuum centrifuge to concentrate the trichodinids in a pellet. Subsequently, based on the study by Tang et al. (2013), the pellet was digested, and its genomic DNA was extracted using the REDExtract-N-Amp TM Tissue PCR Kit (Sigma, St. Louis, USA) following the manufacturer's instructions.

The 18S rRNA gene of $T$. rectuncinata was amplified by the polymerase chain reaction (PCR) with the following primers: forward primer 5'-AAC CTG GTT GAT CCT GCC AGT-3' and reverse primer 5'-TGA TCC TTC TGC AGG TTC ACC TAC-3' (Medlin et al., 1988). The cycling condition for PCR were: initial denaturation al $94^{\circ} \mathrm{C}$ for one min, 5 step cycling of denaturation at $94^{\circ} \mathrm{C}$ for one min, alignment at $56^{\circ} \mathrm{C}$ for $2 \mathrm{~min}$ and extension at $72^{\circ} \mathrm{C}$ for $2 \mathrm{~min}$, followed by 35 cycles similarly to the previous cycles, with the difference of the temperature of the alignment period which increased to $62^{\circ} \mathrm{C}$, and finally an extended elongation step at $72^{\circ} \mathrm{C}$ for $10 \mathrm{~min}$. PCR reactions were performed with REDExtract-N-Amp PCR Reaction Mix, following the manufacturer's instructions. The amplified products were evaluated by electrophoresis on a $1 \%$ agarose gel with the Tris-Acetate buffer (TAE 1X). Sequencing reactions were made with the two PCR primers used ABI Big Dye terminator sequencing chemistry (Applied Biosystems, Boston, Massachusetts, USA), in the Laboratorio de Biología Molecular de la Biodiversidad y la Salud of the Universidad Nacional Autónoma de México (IBUNAM), Mexico. The readings of the sequences were assem- 


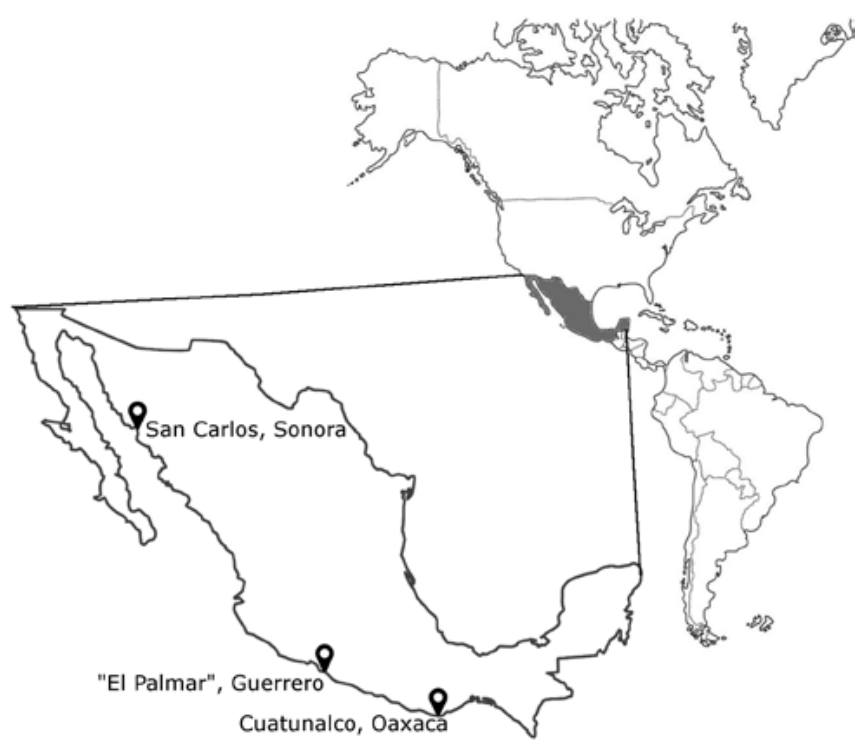

Fig. 1. Map showing the location of Mexico, and localities where populations of Trichodina rectuncinata were obtained.

bled in Geneious Pro 4.8.4 (Biomatters Ltd., Auckland, New Zeland) to generate consensus sequences.

The consensus sequences were compared in the database of the genbank using the search of similarity with the BLAST (https:// blast.ncbi.nlm.nih.gov/Blast.cgi) option selected (Basic Local Alignment Search Tool). Sequences were submitted into the GenBank database (accession numbers MK076565-MK076575).

\section{Phylogenetic Analyses}

Based on 11 partial 18S rRNA gene sequences corresponding to the reverse region of populations of Trichodina rectuncinata, a multiple alignment was performed using SATé version 2.2.7 under the default settings (Liu et al. 2009, 2012), and generating an aligned dataset of $500 \mathrm{bp}$.

Then, the genetic divergence between these sequences was estimated with uncorrected " $p$ " distances using the program Mega version 6.0 (Tamura et al. 2013). To test the phylogenetic position of the obtained sequences with respect to other congeners, a new multiple alignment was built using the procedure described above for the 11 sequences from $T$. rectuncinata along with sequences of other 11 trichodinid species downloaded from the GenBank dataset plus Urceolaria urechi which was used as the outgroup for rooting the tree. As a result, a dataset of 1745 bp was generated. Later, Bayesian Inference (BI) and Maximum likelihood (ML) analyses were used for tree construction. The Bayesian analyses was performed using the MrBayes program (Ronquist et al. 2012) with the following parameters: runs of eight Markov chains for 10,000,000 generations, starting from one random tree, sampling every 1000 generations. The ML tree and 1000 bootstrap were calculated using RAxML (Stamatakis 2014), with the GTRGAMMA model.

\section{RESULTS}

From all examined fish species, only Network Triplefin (Enneanectes reticulatus), Rock Blenny (Entomacrodus chiostictus), and Zebra Clingfish (Tomicodon zebra) were infested with Trichodina rectuncinata. Morphological characterization was performed from specimens collected in E. reticulatus (San Carlos), and T. zebra (Zihuatanejo and Cuatunalco). Specimens collected from $E$. chiostictus were very scarce and the deficient impregnation of these ciliates did not allow their accurate characterization. Instead, the molecular analysis was conducted from samples from the three-fish species.

Based on the shape of denticles, we found four different morphotypes for $T$. rectuncinata (Fig. 2). Morphotypes $a$ and $b$ were present on the same host species E. reticulatus from San Carlos. Morphotype $a$ exhibited a triangular blade with straight edges parallel to $\mathrm{Y}$ axis and with a wide triangular cavity, short central part and a large and straight ray, occasionally short (Fig. 2a and a'); while morphotype $b$ showed a slightly curved blade, in some cases clearly curved, central part developed in most cases above the $\mathrm{X}$ axis, and a large ray, which touch the $\mathrm{Y}$ axis in most of the cases. (Fig. $2 \mathrm{~b}$ and b'). A third morphotype (c) was found in T. zebra from Zihuatanejo, the features of the denticles in this ciliate population showed a short and slightly curved blade with a small pyriform cavity, a wide and triangular central part, which occurs on the posterior part of the $\mathrm{Y}$ axes, and a wide and short ray, which ends round (Fig. 2c and c'). Morphotype $d$ was found in ciliates recovered from T. zebra from Cuatunalco. This morphotype is characterized by having a triangular blade with a wide and triangular cavity, a very thin central part, which crosses the $\mathrm{Y}$ axis, and a short, stout ray with strongly rounded end (Fig. $2 \mathrm{~d}$ and d').

This morphological variability does not correspond with the genetic divergence, which varied from $0 \%$ to a maximum of $1.7 \%$ (mean $0.97 \%$ ), suggesting that all analyzed populations belong to the same species. Interestingly, the lowest divergence value between localities was presented by those more distant (San Carlos and Cuatunalco, Table 1) (mean $0.32 \%$ ), while divergence between populations of Zihuatanejo and Cuatunalco (mean 1.06\%) were higher even though localities are geographically closer, and they were collected from the same host species, T. zebra.

The BI analysis showed that the sequences of Trichodina rectuncinata are grouped in a single clade, 
148 A. G. Islas-Ortega et al.
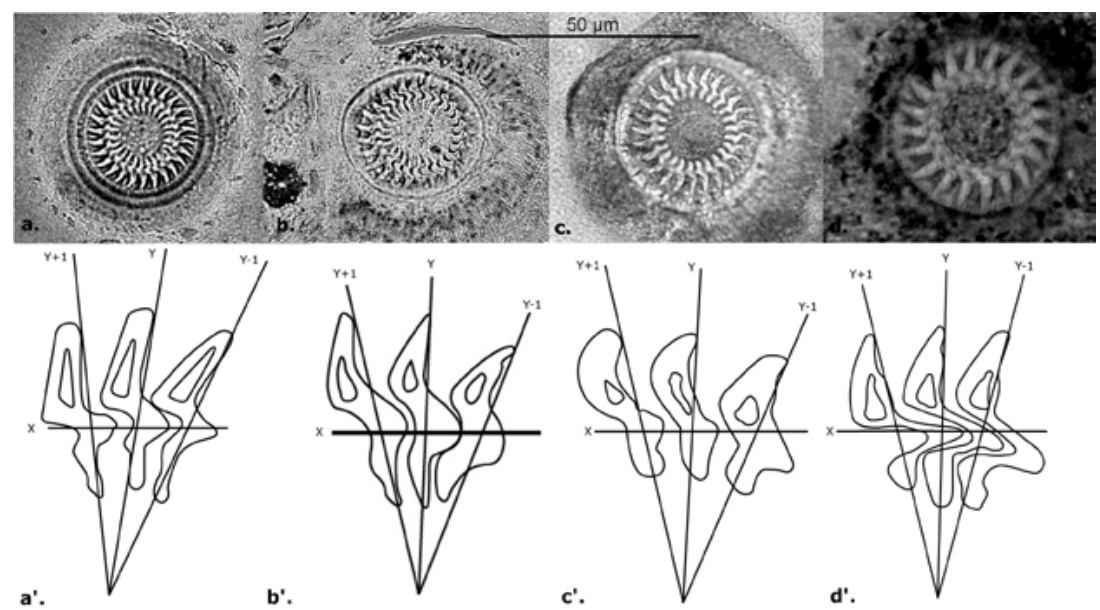

Fig. 2. Photomicrographs of silver-impregnated adhesive discs and diagrammatic drawings of the denticles of respective morphotypes studied in the present paper; a and a'. From Enneanectes reticulatus, San Carlos, Sonora. b and b'. From Enneanectes reticulatus, San Carlos, Sonora. c and c'. From Tomicodon zebra, Zihuatanejo, Guerrero. d and d'. From Tomicodon zebra, Cuatunalco, Oaxaca.

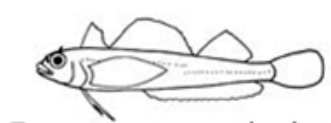

Enneanectes reticulatus

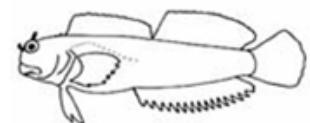

Entomacrodus chiostictus

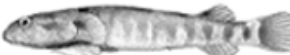

Tomicodon zebra

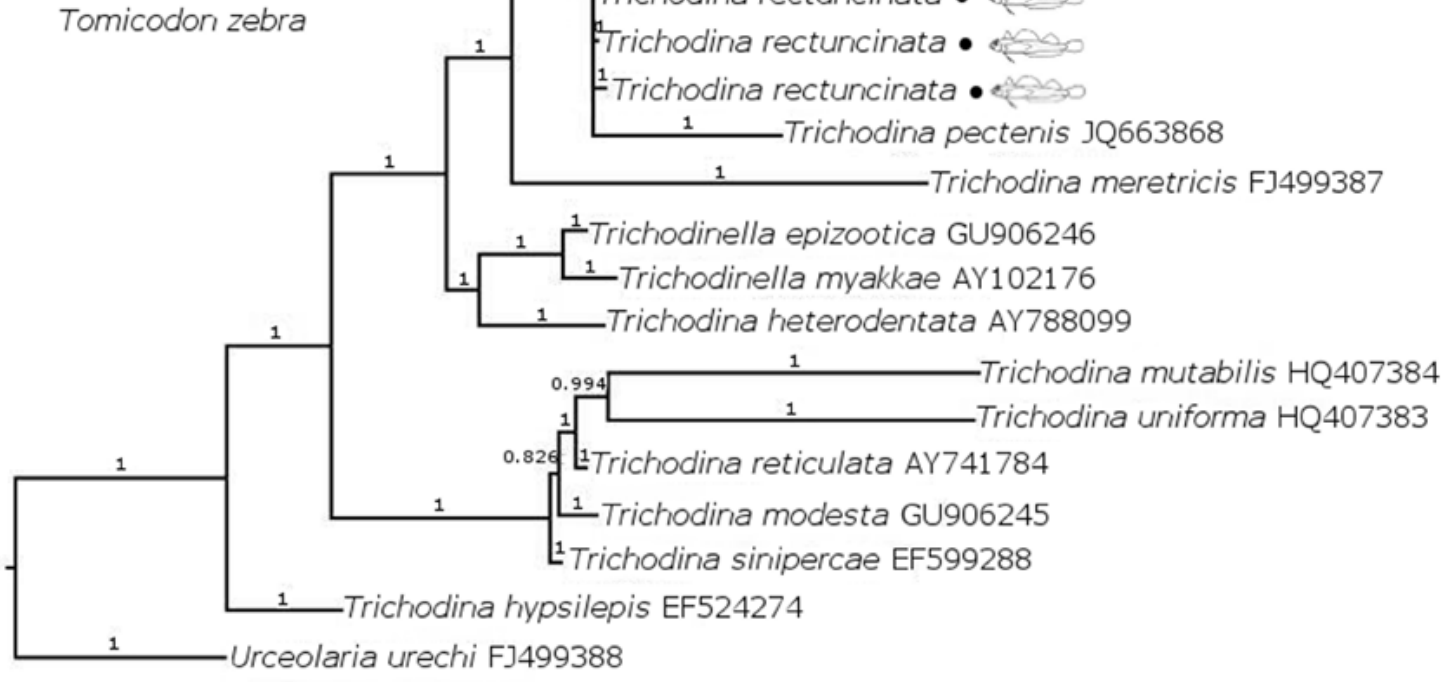

0.2

Fig. 3. Bayesian inference tree of sequences of the $18 \mathrm{~S}$ gene of trichodinid species of the genus Trichodina and Trichodinella, emphasizing on Trichodina rectuncinata. Numbers near internal nodes show the support value. Codes: Cuatunalco; * Zihuatanejo; $\bullet$ San Carlos. 


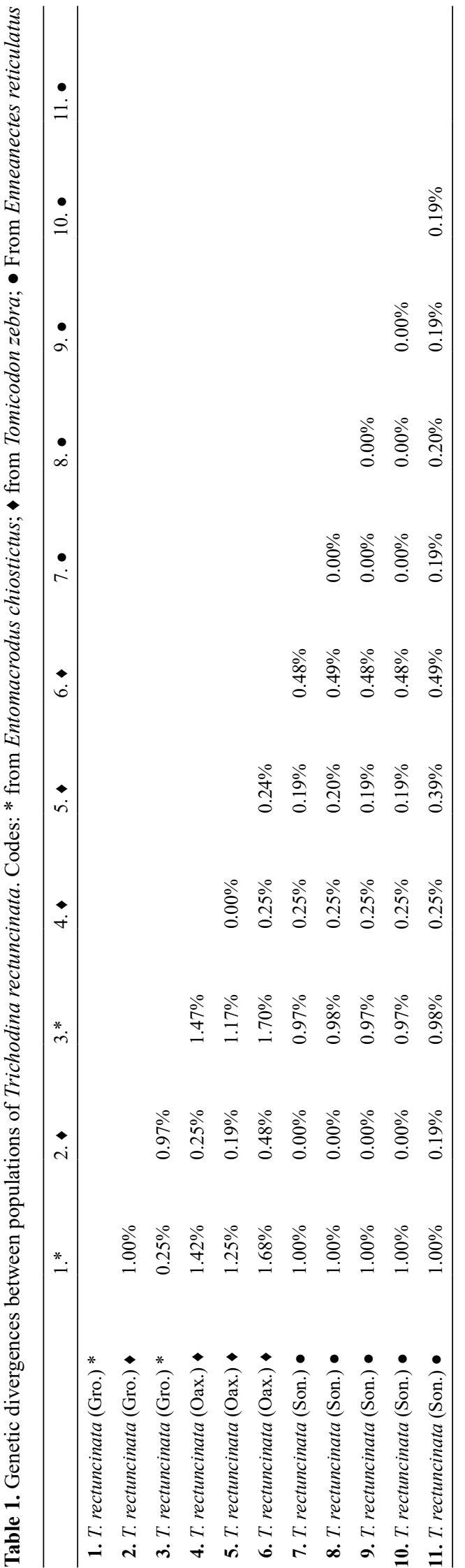

with T. pectenis as sister species (Fig. 3), this relationship is supported by the highest posterior probability value (1.0). The ML analysis produced a single tree $(-\mathrm{InL}=8676.19)$, where samples of $T$. rectuncinata are also grouped in a single clade, with relatively high bootstrap support value (81) (Fig. 4), T. pectenis is also recovered as a sister group. Phylogenetic relationships among remaining trichodinid species used in the analysis were identical in both trees. The grouping of analyzed sequences of $T$. rectuncinata in a single clade is congruent with the values of genetic divergence, suggesting that examined populations belong to the same species.

\section{DISCUSSION}

Trichodina rectuncinata is a widely distributed ciliate species which has been reported from marine fishes of at least 17 not closely related fish families: Balistidae, Blennidae, Cottidae, Gadidae, Gobiesocidae, Gobiidae, Hexagrammidae, Labridae, Lateolabracidae, Lotidae, Moridae, Mullidae, Scianidae, Scorpaenidae, Serranidae, Sygnathidae, and Tripterygiidae (see Lom and Dyková 1992; Xu et al. 2001; Aguilar-Aguilar et al. 2016). This wide host spectrum suggests a moderate ecological specificity; even though this ciliate species has been reported from numerous fish taxa, it seems to prefer benthic fishes. In this study, we conducted a morphometric-molecular analysis of three populations of $T$. rectuncinata to evaluate potential differences among $18 \mathrm{~S}$ rRNA sequences, in relation to morphological variations. However, our results did not show a significant genetic divergence for the used marker. Sequences exhibited very low genetic divergence among analyzed populations, ranging from 0 to $1.7 \%$.

In concordance with these results, the ML and BI trees inferred from the $18 \mathrm{~S}$ RNA data set in this study consistently showed that the analyzed sequences of T. rectuncinata are grouped as populations of the same species, which exhibited a wide morphological variability. These results are based on partial sequences of only one ribosomal gene, which was able to provide accurate phylogenetic inferences because most of the molecular information currently available for trichodinids have been generated for these genes. A further study using other molecular markers such as the mitochondrial gene COI, and other nuclear markers such as LSU and ITS, in a more extensive geographical spectrum, will allow to 


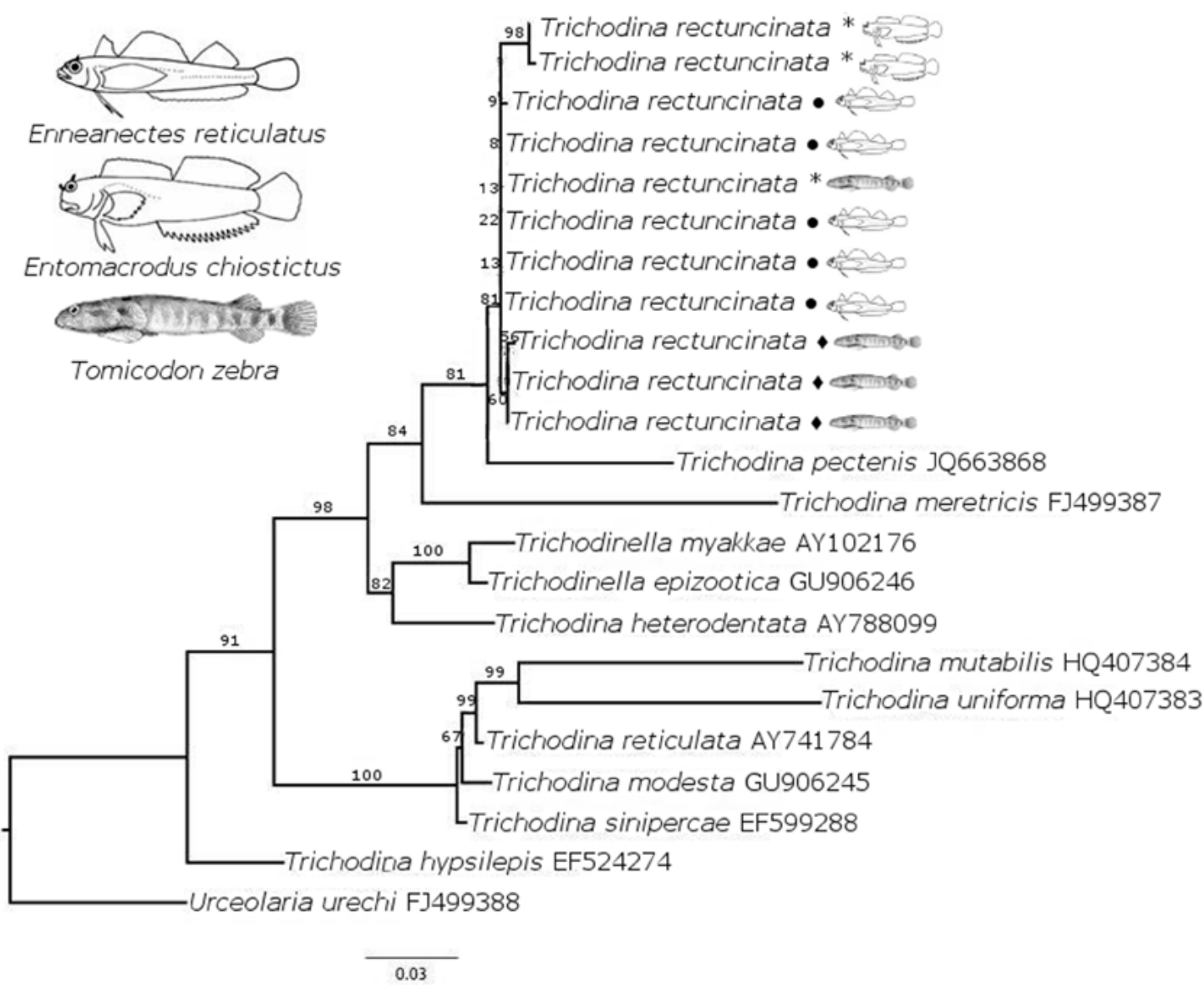

Fig. 4. Maximum likelihood of sequences of the $18 \mathrm{~S}$ gene of trichodinids of the genus Trichodina and Trichodinella, emphasizing on Trichodina rectuncinata. Numbers near internal nodes show the bootstrap values. Codes: $\bullet$ Cuatunalco; * Zihuatanejo; • San Carlos.

corroborate the hypothesis that morphological variation among populations of $T$. rectuncinata is host-induced, and not the result of a speciation process even though this has been suggested by several authors (Grupcheva et al. 1989; Loubser et al. 1995; Xu et al. 2001). Additional molecular data may probably reveal the existence of several lineages, and the potential existence of cryptic species, such as frequently found in other parasitic species (Nadler and Pérez-Ponce de León 2011).

In conclusion, in the present study we used a molecular marker to determine whether or not a morphologically variable species of ciliate represents a single species considering that $T$. rectuncinata is widely distributed in marine fish along the Pacific coast of Mexico. We found no correlation between morphological variation and genetic divergence for this species with the molecular marker used. Further analyses using more variable markers are necessary to corroborate the findings of our study. However, this work represents a first step in the elucidation of the phylogeographical patterns of trichodinids. Also, we contributed adding sequence data to the genetic library that would be increased in the near future.

Acknowledgements. We thank Dr. Gerardo Rivas (Facultad de Ciencias, UNAM), Dr. Gabriela Parra Olea, M. en C. Berenit Mendoza Garfias, and M. en C. Laura Márquez Valdelamar (Instituto de Biología, UNAM) and Ana O. Santacruz (UNAM) for support in the field or laboratory. The first author was benefited from a scholarship from the Consejo Nacional de Ciencia y Tecnología (CONACYT) to complete her MSC program; the financial support from the Programa de Apoyo a los Estudios de Posgrado (PAEP), and the Programa de Posgrado en Ciencias Biológicas, Universidad Nacional Autónoma de México is greatly appreciated. 


\section{REFERENCES}

Aguilar-Aguilar R., Islas-Ortega A. G. (2015) A checklist of ciliate parasites (Ciliophora) of fishes from Mexico. Zootaxa 4027: $270-280$

Aguilar-Aguilar R., Islas-Ortega A. G., Lagunas-Calvo O., López N., Espinosa-Pérez H. (2016) New host parasite relationships for Trichodina rectuncinata (Ciliophora: Trichodinidae) on the gills of marine fishes from Mexico. Mar. Biodiv. 46: 3-4

Basson L., Van As J. (2006) Trichodinidae and other ciliophorans (Phylum Ciliophora). In: Fish diseases and disorders, Volume 1: Protozoan and metazoan infections, $2^{\text {nd }}$ Edition (Eds, P. T. K. Woo, J. F. Leatherland). CAB International, Cambridge, $154-182$

Blouin M. S. (2002) Molecular prospecting for cryptic species of nematodes: mitochondrial DNA versus internal transcribed spacer. Int. J. Parasitol. 32: 527-531

Dobberstein R. C., Palm H. W. (2000) Trichodinid ciliates (Peritrichia: Trichodinidea) from the Bay of Kiel, with the description of Trichodina claviformis sp. n. Folia Parasitol. 47: 81-90

Grupcheva G., Lom J., Dyková I. (1989). Trichodinids (Ciliata: Urceolariidae) from gills of some marine fishes with the description of Trichodina zaikai sp. n. Folia Parasitol. 36: 193-207

Liu K., Raghavan S., Nelsen S., Linder C. R., Warnow T. (2009). Rapid and accurate large-scale coestimation of sequence alignments and phylogenetic trees. Science 324: 1561-1564

Liu K., Warnow T., Holder M., Nelsen S., Yu J., Stamatakis P., Linder R. (2012). SATé-II: Very fast and accurate simultaneous estimation of multiple sequence alignments and phylogenetic trees. Syst. Biol. 61: 90-106

Lom J. (1958) A contribution to the systematic and morphology of endoparasitic trichodinids from amphibians, with a proposal of uniform specific characteristics. J. Protozool 5: 251-263

Lom J., Dyková I. (1992) Protozoan parasites of fishes. Elsevier Science Publishers, Amsterdam

Loubser G. J., Van As J. G., Basson L. (1995) Trichodinid ectoparasites (Ciliophora: Peritrichida) of some fishes from the Bay of Dakar, Senegal (West Africa). Acta Protozool. 34: 211-216

Maciel P. O., Garcia F., Chagas E. C., Fujimoto R. Y., Tavares-Dias M. (2018) Trichodinidae in comercial fish in South America. Rev. Fish Biol. Fisheries 28: 33-56

Martorelli S., Marcotegui P., Alda P. (2008) Trichodina marplatensis sp. n. (Ciliophora: Trichodinidae) from Conbjelly, Mnemiopsis mccradyi (Mayer, 1900) in Argentine sea. Acta Protozool. 47: $257-261$.
Medlin L., Elwood H., Stickel S., Sogin M. (1988) The characterization of enzymatically amplified eukaryotic 16S-like rRNAcoding regions. Gene 71: 491-499

Nadler S. A., Adams B. J., Lyons E. T., DeLong R. L., Melin S.R. (2000) Molecular and morphometric evidence for separate species of Uncinaria (Nematoda: Ancylostomatidae) in California sea lions and northern fur seals: hypothesis testing supplants verification. J. Parasitol. 86: 1099-1106

Nadler S. A., Pérez-Ponce de León G. (2011) Integrating molecular and morphological approaches for characterizing parasite cryptic species: implications for parasitology. Parasitology 138: 1688-1709

Pérez-Ponce de León G., Nadler S. A. (2010) What we don't recognize can hurt us: a plea for awareness about cryptic species. J. Parasitol. 96: 453-464

Ronquist F., Teslenko M., van der Mark P., Ayres D. L., Darling A., Höhna S., Larget B., Liu L., Suchard M. A., Huelsenbeck, J. P. (2012) MrBayes 3.2: Efficient Bayesian phylogenetic inference and model choice across a large model space. Syst. Biol. 61: 539-542

Stamatakis A. (2014) RAxML Version 8: A tool for phylogenetic analysis and post-analysis of large phylogenies bioinformatics 10.1093/bioinformatics/btu033

Tamura K., Stecher G., Peterson D., Filipski A., Kumar S. (2013) MEGA6: Molecular evolutionary genetics analysis version 6.0. Mol. Biol. Evol. 30: 2725-2729

Tang F., Zhao Y., Warren A. (2013) Phylogenetic analyses of trichodinids (Ciliophora, Olygohymenophora) inferred from 18S rRNA gene sequence data. Curr. Microbiol. 66: 306-313

Tang F., Zhang Y., Zhao Y. (2017) Morphological and molecular identification of the new species, Trichodina pseudoheterodentata sp. n. (Ciliophora, Mobilida, Trichodinidae) from the channel catfish, Ictalurus punctatus, in Chongqing China. J. Eukaryot. Microbiol. 64: 45-55

Van As J. G., Basson L. (1989) A further contribution to the taxonomy of the Trichodinidae (Ciliophora: Peritrichia) and a review of the taxonomic status of some fish ectoparasitic trichodinids. Syst. Parasitol. 14: 157-179

Xu K., Song W., Warren A., Choi J. K. (2001) Trichodinid ectoparasites (Ciliophora: Peritrichida) of some marine fishes from coastal regions of the Yellow Sea and Bohai Sea. Syst. Parasitol. 50: 69-79

Received on $6^{\text {th }}$ March, 2018; revised on $3^{\text {rd }}$ May, 2018; accepted on $4^{\text {th }}$ May, 2018 